

ORIGINAL ARTICLE

\title{
Structural optimization of concrete plane frames considering the static and dynamic wind effect
}

\section{Otimização estrutural de pórticos planos de concreto considerando o efeito estático e dinâmico do vento}

\author{
Emanuely Ugulino Cardoso ${ }^{\mathrm{a}}$ \\ Rene Quispe Rodríguez ${ }^{\mathrm{b}}$ \\ Lucas Queiroz Machadoc ${ }^{c}$ (iD \\ Felipe Faustino Kunz ${ }^{\mathrm{d}}$ \\ Patrick dos Santos e Santos ${ }^{\mathrm{e}}$ \\ Alana Paula da Costa Quispe ${ }^{\mathrm{f}}$ (D)
}

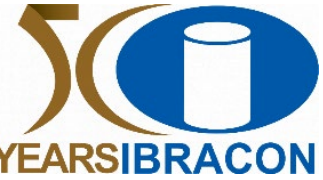

\footnotetext{
${ }^{a}$ Universidade de Brasília - UnB, Faculdade de Tecnologia, Brasília, DF, Brasil

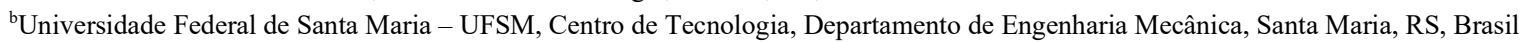

${ }^{\mathrm{c} S}$ School of Engineering and Physical Sciences, Heriot-Watt University, Edinburgh, Scotland

${ }^{\mathrm{d}}$ Universidade do Estado de Mato Grosso - UNEMAT, Departamento de Engenharia Civil, Tangará da Serra, MT, Brasil

${ }^{\text {e} U n i v e r s i d a d e ~ d o ~ E s t a d o ~ d e ~ S a n t a ~ C a t a r i n a ~-~ U D E S C, ~ C e n t r o ~ d e ~ C i e ̂ n c i a s ~ T e c n o l o ́ g i c a s, ~ D e p a r t a m e n t o ~ d e ~ E n g e n h a r i a ~ M e c a ̂ n i c a, ~ J o i n v i l l e, ~ S C, ~ B r a s i l ~}$

fUniversidade Federal de Santa Maria - UFSM, Centro de Tecnologia, Programa de Pós-graduação em Engenharia Civil - PPGEC, Santa Maria, RS, Brasil
}

Received 02 March 2021

Accepted 07 June 2021

\begin{abstract}
This study has as its main purpose the structural optimization of plane frames in concrete, having as the objective function the minimum total weight of the structure. For this purpose, external actions, considered within the optimization process, are intended to represent accurately all effects observed in a real situation. In such manner, loads are dependent on the cross-section obtained in each optimization step, as well as the static and dynamic effects of the wind are considered for a more realistic representation. The optimization method adopted is the Teaching-Learning Based Optimization (TLBO). Thus, all proper design constraints were considered in accordance with Brazilian standards for concrete structures. From the results obtained in both situations (static and dynamic effects), it is possible to notice the difference regarding external actions, in which higher loads were obtained in higher floors, using the simplified dynamic model proposed in standards. Regarding the analysis of the structure optimization, the weight was higher when the applied forces were the result of the dynamic wind model, in which the larger cross-sections were found at the bottom of the structure. Even though this may be a well-known issue, the present work shows a quantitative study in which both effects are discussed in detail, as well as it features a methodology, based on a novel optimization method and with a straightforward implementation, that could be adapted for the analysis of more complex structures.
\end{abstract}

Keywords: finite element method, teaching-learning-based optimization, structural weight, Brazilian standards.

Resumo: O presente estudo tem como objetivo principal a otimização estrutural de pórticos planos de concreto, tendo como função objetivo o mínimo peso total da estrutura. Para este fim, ações externas, consideradas dentro do processo de otimização, tratam de representar de forma precisa todos os efeitos presentes em uma situação real. Desta forma, os carregamentos são dependentes das áreas da seção transversal obtidas em cada passo da otimização, assim como os efeitos estáticos e dinâmicos do vento são considerados para uma representação mais realista. O método de otimização adotado é o método de otimização baseado em ensino-aprendizagem, ou Teaching-Learning Based Optimization, em inglês. Além do mais, todas as restrições para um projeto adequado são consideradas usando as normas brasileiras para estruturas de concreto. Dos resultados obtidos em ambas as situações (estática e dinâmica), é possível notar a diferença com respeito às ações externas, onde maiores carregamentos são obtidos em pisos mais altos, usando a modelo dinâmico simplificado proposto em normas. Com respeito à análise de otimização, o peso foi maior no caso

Corresponding author: Rene Quispe Rodríguez. E-mail: rene.rodriguez@ufsm.br

Financial support: None.

Conflict of interest: Nothing to declare.

This is an Open Access article distributed under the terms of the Creative Commons Attribution License, which permits unrestricted use, distribution, and reproduction in any medium, provided the original work is properly cited. 
dinâmico, onde maiores áreas transversais foram necessárias. Apesar deste fato ser conhecido, o presente trabalho mostra um estudo quantitativo onde ambos os efeitos são discutidos em detalhes, assim como é apresentada uma metodologia, baseada em um método de otimização original e de fácil implementação, que pode ser adaptada à análise de estruturas mais complexas.

Palavras-chave: método dos elementos finitos, otimização baseada em ensino-aprendizagem, peso estrutural, normas brasileiras.

How to cite: E. U. Cardoso, R. Q. Rodríguez, L. Q. Machado, F. F. Kunz, P. S. Santos, and A. P. C. Quispe, "Structural optimization of concrete plane frames considering the static and dynamic wind effect," Rev. IBRACON Estrut. Mater., vol. 15, no. 1, e15109, 2022, https://doi.org/10.1590/S1983-41952022000100009

\section{INTRODUCTION}

High building construction trend is increasing over recent years, due to factors such as urban sprawl and high land costs, stimulating the construction of cost-effective structures and bracing systems, as these buildings are mainly affected by lateral loads induced by wind effects [1]. Tall and slender structures have, in general, low frequencies and small rates of damping and under the action of dynamic environmental forces, such as those generated by the wind, can present great amplitude of oscillation, causing problems related to the comfort of users, use in service and even safety and service life of the structure [2]. Structures can be defined as physical systems subject to external actions, capable of transmitting efforts, and these actions are called dynamics when they generate forces of inertia [3]. An accurate realistic analysis should include the dynamic response of effects of resonance, acceleration, damping and structural stiffness variation [4]. Furthermore, external actions can cause vibrations in the structures and affect the users' comfort, in which the slender buildings are more susceptible to these effects. Generally, structural designs consider the wind effect wind as static loads, calculated from the average speed, without considering the components of the fluctuation part that can induce vibrations in the structural system. Thus, for a more realistic and reliable analysis, the dynamic characteristics of the wind must be considered, in such a way that the fluctuation part is used in dynamic modeling, in which the largest transfer of wind energy in the structure is concentrated in regions with low frequencies [5]. Structural design needs to find optimal dimensions for the elements when subjected to different loads [6]. Thus, structural optimization seeks to assist in the engineering area the determination of structures that offer the best performance. Concrete structures have good characteristics of durability and resistance to compression, being a material with wide use. However, most practical optimization procedures for concrete structures are based on iterative procedures, which may guarantee structural safety, but may not result in optimal structures [7].

Tapajós et al. [8] investigated the wind effect and its dependence on the concrete structure sizing and its foundation. Their study considered 10, 20 and 30 -story buildings with and without the wind effect. Results indicated that even for a 10-story building, the wind effect played an important role in the general security of the edification. Regarding the optimization of structural systems. Kripka et al. [9] studied the optimum spacing for concrete reinforced columns in building structures, aiming to minimize the total global cost in terms of concrete, steel and formworks use. The authors modeled the system using beam elements supported by springs with rotational rigidity. The design variables considered were geometric parameters of both beams and columns, while the optimization process consisted in an iterative process with removal of the less stressed columns. The results obtained were like those already used in practical cases. Breda et al. [10] presented a numerical optimization process, using the commercial software MATLAB as the main computational tool, for the optimization of steel-concrete composite beams and steel deck systems. The study demonstrated that increasing the number of beams, while reducing its individual weight, results in smaller slab spans and, consequently, in a reduction of the overall weight and costs. Recently, Gomez et al. [7] studied the topology optimization of buildings under wind stochastic loads. In this study the wind was modeled as a filtered white noise, while the optimization was accounted with a gradient-based method. The optimization procedure demonstrated high efficiency for tall buildings.

The present work aims to analyze the performance of concrete frame structures, subjected to both permanent and variable loads. The main objective is to optimize this kind of structure, using a metaheuristic optimization method based on a teaching-learning framework, namely teaching-learning-based optimization method (TLBO). The objective function is to minimize the total weight of the structure by minimizing the cross-section (design variable) of its components, which characterize a parametric optimization. The constructive constraints were those required by the Brazilian normative NBR 6118:2014 [11] and are in terms of specific maximum displacements and stresses. The optimization process is applied to two different situations, considering both a static wind analysis and the simplified dynamic effect according to the Brazilian standard NBR 6123:1988 [12]. 


\section{THEORETICAL BACKGROUND}

\subsection{Structural Optimization}

The optimization process seeks to maximize or minimize a certain objective function, within a domain that contains the acceptable values of the variables that will be processed, in such a way that the imposed constraints are satisfied. The best solution to the problem is designated as the optimal solution. Structural optimization, in many cases, is related to the interest in reducing costs. A relatively direct way of doing so is to find the minimum cross sections areas, reducing the overall structural weight, and a consequence, decreasing the material costs. Thus, some constraints can be considered, such as stresses and displacements. The optimization problem of minimizing the total weight of the structure can be defined as [13]. Minimize the weight objective function $w$ :

$$
w=\sum_{e=1}^{N_{m}} \gamma_{e} L_{e} A_{e},
$$

subject to stress constraints $\sigma$ and displacements $\delta$ :

$$
\sigma^{L} \leq \sigma_{e} \leq \sigma^{U} \text { and } \delta^{L} \leq \delta_{e} \leq \delta^{U}
$$

where $w$ is the weight of the structure composed of $N_{m}$ members; $\gamma_{e}$ is the unit weight of the material of each member; $L_{e}$ the length, $A_{e}$ determines the cross section. The solution must meet the stress limits $\sigma$ and displacement $\delta$, where $L$ is defined as the lower limit and $U$ as the upper limit. To account for elements that have not met the constraints, a penalty function is used, in such a way that the weight of the structure will be multiplied by the penalty factor. If the stress and displacements are within the stipulated limits, it will not suffer a penalty; otherwise, the stress penalty $\phi_{\sigma}^{e}$ for each element can be defined as

$$
\phi_{\sigma}^{e}=\left|\left(\sigma_{e}-\sigma^{L, U}\right) / \sigma^{L, U}\right|^{L}
$$

The total stress penalty $\phi_{\sigma}^{k}$ for the design of a $k$ structure being the sum over all elements. The penalty for displacement can be obtained in the same way, hence, the value of the total penalty $\psi^{k}$ for a structure, can be calculated by

$$
\psi^{k}=\left(1+\phi_{\sigma}^{k}+\phi_{\delta}^{k}\right)^{r}
$$

where $r$ is a positive penalty exponent. The penalized value that determines the weight of the structure by multiplying is real weight with the penalty $\psi^{k}$. Thus, the weight of the analyzed project is increased, as the elements that did not meet the constraints are penalized. The procedure continues until the optimal structure is obtained.

\subsection{Teaching-Learning Based Optimization (TLBO)}

The TLBO is a meta-heuristic optimization method that follows the analogy of the participation of a teacher and students in a class. The method is subdivided into two different consecutive processes: the teacher phase, that simulates his influence onto students; and a student phase, which models collaborative learning among students [14]. The teacher is considered the most educated person, who shares his knowledge and his ability to influence the class average, because the greater the teacher's capacity, the greater the average achieved by the class. In the same way that the interaction between the students themselves also improves the individual performance of each student [15]. Relating the TLBO method to an optimal structure design, the following relationships can be established: (1) a class of students represents the size of the population to be analyzed; (2) the design variables are considered as the subjects offered to students; and (3) the grade is the result of the structure weight, and the teacher is considered as the best solution obtained. This process is carried out until the objective function is minimized according to the imposed constraints [16]. 


\section{Definition of the problem and optimization parameters}

First, the number of students (population size), the stopping criteria (maximum number of iterations), the number of subjects (design variables) and the limits of the design variables (stresses and displacements) are defined. The matrix that represents the class is filled up with randomly generated students, according to the population size and the number of project variables [16].

\section{Teacher phase}

The influence of the teacher is considered, verifying the improvement of the knowledge of the students, based on the information transmitted by the teacher. In the optimization process, the design vector relates a student's current knowledge in different disciplines. Thus, the student's learning during this interaction with the teacher is expressed as:

$$
X_{\text {new }}^{k}(j)=X_{\text {old }}^{k}(j) \pm \Delta(j), \Delta(j)=T_{F} * r|M(j)-T(j)|,
$$

where $X^{k}(j)$ indicates the $j$-th design variable for the $k$-th design vector; $T_{F}$ is the teaching factor; $r$ is a random number uniformly distributed within the range of $[0,1] ; M(j)$ is the class average; $T(j)$ is the teacher's status; and $\Delta(j)$ indicates the difference between the teacher and the class average for each design variable, and its sign must be selected so that the student always move towards the teacher. The $T_{F}$ teaching factor is used to increase the size of the local search space around each student and can take the value of 1 or 2 [14]. A modification of the TLBO method was proposed by Camp and Farshchin [14]. The class average is calculated by a weighted average based on the student's grade (structure weight), to give more emphasis to the most qualified students, and is defined by:

$$
M(j)=\sum_{k=1}^{n p} \frac{X^{k}(j)}{F^{k}} / \sum_{k=1}^{n p} \frac{1}{F^{k}} .
$$

If the calculation shows that $X_{\text {new }}^{k}(j)$ is better than the previous $X_{\text {old }}^{k}(j)$, the new solution will be replaced by the current solution, otherwise the old solution will be maintained.

\section{Learner phase}

It analyzes the interaction between students in a class, to improve their knowledge and improve the performance of the class. A given solution interacts randomly with other solutions to obtain new information [15]. The procedure starts with a random choice of two students in the class, $p$ and $q(p \neq q)$. Then, the aptitude of each student is analyzed, $p$ being considered as the most qualified student, aiming to improve his individual performance [14]. Considering that $F^{p}$ and $F^{q}$ are the students' grades and represent, in structural optimization, the weight of the structure, the following criteria are analyzed to determine the new solution. If $F^{p}<F^{q}$ :

$$
X_{\text {new }}^{p}(j)=X_{\text {old }}^{p}(j)+r\left[X_{\text {old }}^{p}(j)-X^{q}(j)\right]
$$

When student $p$ is better than student $q$, he goes in the opposite direction. If $F^{p}>F^{q}$ :

$$
X_{\text {new }}^{p}(j)=X_{\text {old }}^{p}(j)+r\left[X^{q}(j)-X_{\text {old }}^{p}(j)\right]
$$

However, when the student $q$ shows better performance, the student $p$ tends to approach $q$ to become better. In Equation 18, $r$ is a random number uniformly distributed within the range [0,1]. In either case, student $p$ is trying to improve his performance, and his movement tends to go towards the best solution. The value of $X_{\text {new }}^{p}(j)$ is accepted if it provides a better value for the objective function. The process is maintained until the best solution is found, ending when the algorithm converges to an optimal solution or reaches the maximum number of iterations. Figure 1 shows the flowchart of the optimization method identifying the steps performed. 


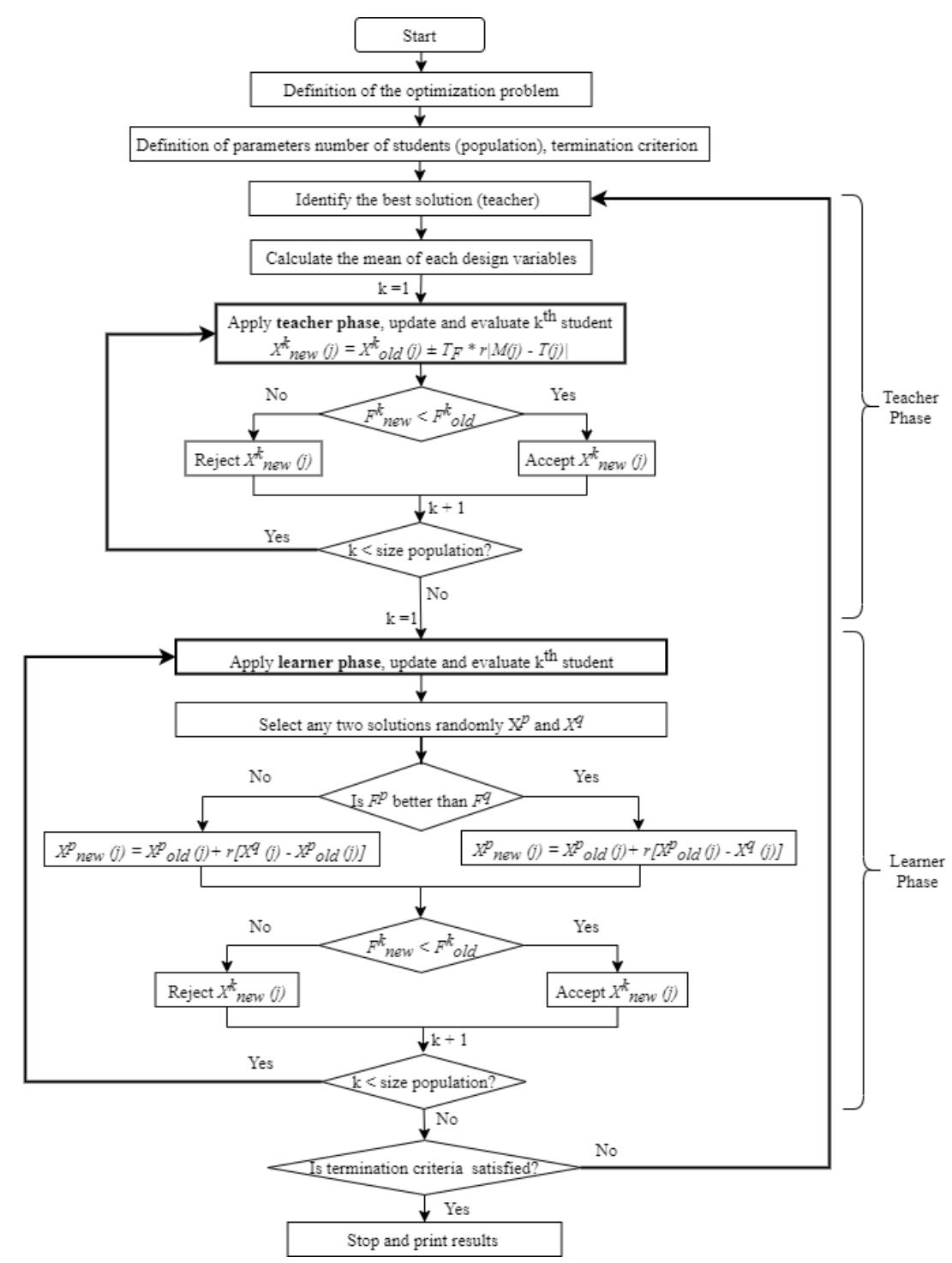

Figure 1. Flowchart for Teaching-Learning Based Optimization (TLBO), based on [20].

\subsection{Methods for analyzing the influence of the wind}

The structural wind effect occurs randomly on buildings, affecting, generally, all horizontal directions. In this manner, the most critical situation should be accounted for a proper structural design [16]. According to Chávez [17], the study of the wind effect in buildings should consider static and dynamic solicitations, both depending on the mean velocity and its fluctuations. These fluctuations are the gusts or turbulence that give rise to vibrations due to the various ways in which their force acts on the structure, producing a short-term random loading that makes direct stress analysis difficult. According to Islam et al. [18], the adequate control of the lateral deflection of buildings should allow the non-structural components to function correctly, avoid wear on the structure and the appearance of excessive deflection cracks, which, consequently, cause the loss of stiffness. When dimensioning a structural system, it must be rigid enough to avoid dynamic movements due to wind loads and any load redistribution to unplanned locations. The Brazilian standard NBR 6123:1988 [12], regulates the study of the effects of winds on structures and specifies the conditions required to consider the forces due to static and dynamic wind action, for the purpose a proper building design calculation.

\section{Static wind analysis according to NBR 6123:1988 [12]}

The Brazilian standard NBR 6123:1988 [12] presents a procedure for considering static loads due to the wind. The main aspects of the normative are presented for completeness, nonetheless, the reader can refer to the Brazilian standard 
for more details. The parameters considered for this simplification are the basic wind speed (Vo), suitable for the place where the structure will be built; the factors $S 1, S 2$ and $S 3$, to be obtained the characteristic speed of the wind (Vk), and with the characteristic speed. With this information it is possible to determine the dynamic pressure $(q)$, and finally, obtaining the forces, the pressure and shape coefficients [12].

The basic wind velocity $(\mathrm{Vo})$, obtained from the standard, is defined as the velocity of a $3 \mathrm{~s}$ gust, exceeded on average once in 50 years, $10 \mathrm{~m}$ above ground, in the field open and flat field. It is admitted that the basic wind can blow from any horizontal direction [12]. The topographic factor (S1) considers the topographic characteristics of the land on which the construction will take place. This coefficient is 1.0 for flat or slightly rugged locations, 0.9 for deep windprotected valleys, and has a variation for slope-side buildings [19]. The factor $S 2$ considers the variation of the wind speed according to the roughness of the terrain, height, and dimensions of the construction. Thus, to perform the calculation of this factor one must determine the category to which the building belongs, as well as its class. The category is related to the roughness of the terrain, being established five categories, according to NBR 6123:1988 [12]. For the determination of the class that the building belongs to, one must consider the duration of the gust so that the wind encompasses the entire building, as well as the largest dimension. The Brazilian standard NBR 6123:1988 [12] establishes three classes. It is necessary to consider the category and class to determine the parameters used to calculate the factor $S 2$. The statistical factor (S3) considers five groups for the required degree of security and the useful life of the building. From the values of $V o, S 1, S 2$ and $S 3$ it is possible to calculate the characteristic wind speed, in $\mathrm{m} / \mathrm{s}$, using the following expression:

$V_{k}=V_{o} S 1 S 2 S 3$,

further obtaining the dynamic wind pressure, in $\mathrm{N} / \mathrm{m}^{2}$, as follows

$q=0.613 V_{k}^{2}$

Finally, the force due to the wind effect is calculated by multiplying the dynamic pressure by the area of influence and a pressure coefficient. This coefficient considers the building in external and internal parts, relating to the permeability, the shape of the building and the wind direction in the structure. The coefficients are described by means of tables and abacuses in NBR 6123:1988 [12] and if the difference between the external and internal pressure coefficients is positive, the total effective pressure will have the direction of the external overpressure, otherwise it will have the direction of an external suction [19].

\section{Dynamic analysis by the simplified method of ABNT NBR 6123:1988 [12]}

Dynamic actions cause vibrations in structures, which can not only damage them, but also cause fatigue in their materials, affect the comfort of users and the operation of equipment supported by them [3]. The effects generated by these actions on buildings are even more critical due to the structural characteristics themselves, such as the slenderness of the building. Wind speed fluctuations can cause flexible structures, especially in tall and slender constructions, to move in the direction of average speed, called the floating response. In constructions with a fundamental period of more than $1 \mathrm{~s}$, particularly those that are weakly cushioned, a floating response in the direction of the average wind can be found. The total dynamic response is equal to the superposition of the average and floating responses [12]. Even if the models presented by the standard are called dynamic, the wind loading is considered only as static load. This method is applicable to structures supported exclusively at the base and height less than $150 \mathrm{~m}$, considering only the first mode of vibration for calculating the floating response. In this case, the fundamental frequency of the building, the corresponding vibration mode, and the modal damping, are obtained approximately according to the height of the building and the characteristics of its structural system [17]. The design speed $\left(V_{p}\right)$ is calculated from the basic speed $V o$, as

$V_{p}=0.69 V_{0} S 1 S 3$.

The dynamic pressure $q(z)$, from which forces are obtained, is a continuous function of height above ground and the first term of the expression corresponds to the mean response, while the second is the maximum amplitude of the floating response [12]. The dynamic pressure is expressed through Equation 12. 
$q(z)=q_{0} b^{2}\left[\left(\frac{z}{z_{r}}\right)^{2 p}+\left(\frac{h}{z_{r}}\right)^{p}\left(\frac{z}{h}\right)^{\gamma} \frac{1+2 \gamma}{1+\gamma+p} \xi\right]$

The basic pressure, in $\mathrm{N} / \mathrm{m}^{2}$, can be determined according to Equation 13 .

$q_{0}=0.613 V_{p}^{2}$

The coefficients $b$ and $p$ depend on the roughness of the terrain. The heights used in the calculation are determined as $z_{r}$, the reference height at $10 \mathrm{~m}, h$ the height of the building above the ground measured to the top and $z$ the height above the ground in each coordinate. The values of the coefficients of the dynamic pressure are determined according to standards, and the coefficient $\gamma$ determines the modal form and the dynamic amplification coefficient $(\xi)$ can be obtained by means of abacuses and is in function of the dimensions of the building, the ratio critical damping $(\zeta)$ and frequency $(f)$. The force on the structure is the product of dynamic pressure, pressure coefficients and building size. According to Cerutti [20], the dynamic forces calculated here are obtained as dynamic-equivalent static loads, because they are determined by means of abacuses that simplify the calculations.

\subsection{Concrete Structures}

According to NBR 6118:2014 [11], simple concrete elements are defined as: structural elements made with concrete that does not have any type of armour or that has it in a quantity less than the minimum required for reinforced concrete [11]. In item 24 of this standard, to determine the limit values of the resistant stresses of calculation, we have for compression stress:

$$
\sigma_{c R d}=0.85 \frac{f_{c k}}{\gamma_{c}}
$$

where $f_{c k}$ represents the compressive characteristic strength of concrete and $\gamma_{c}$ is the weighting coefficient of concrete strength, for simple concrete cases one must adopt 1.68. For tensile stress, we have:

$\sigma_{c t R d}=0.85 \frac{f_{c t k, i n f}}{\gamma_{c}}$

where $f_{c t \text {, inf }}$ determines the concrete's resistance to direct traction and can be calculated using Equation 29 or 30; the value of $\gamma_{c}$ is the same used for the compression calculation. The value for the resistance of concrete to direct traction varies according to the fck, being that, for group I concretes, that is, up to class C50 ( $f_{c k}$ up to $\left.50 \mathrm{MPa}\right)$ :

$f_{c t k, \text { inf }}=0.7 * 0.3 f_{c k}^{2 / 3}$

and for group II concretes, that is, from C55 to class C90 ( $f_{c k}$ up to $\left.90 \mathrm{MPa}\right)$ :

$$
f_{c t k, i n f}=0.7 * 2.12 \ln \left(1+0.11 f_{c k}\right)
$$

The modulus of elasticity of the concrete used in a structure can be calculated according to item 8.2 .8 of NBR 6118:2014 [11]. In a basic concrete structure minimum limit values are prescribed, according to NBR 6118:2014 [11]. The objective of determining these limit dimensions is related to avoiding unacceptable performance and to having adequate conditions of execution [11]. As presented in item 13.2 of the standard, the cross section of the beams cannot be less than $12 \mathrm{~cm}$ wide, while for the columns the minimum dimension is $19 \mathrm{~cm}$ so that the cross-section area is also not less than $360 \mathrm{~cm}^{2}$. 


\section{Loading on the slabs}

According to Santos [21], the loading of the slab is transmitted to the beams, which are then applied to the columns. On the slabs, actions arising from the own weight, the weight of coatings and usage loads should be considered. Thus, to obtain these loads, the specific weights are multiplied by the respective thicknesses, as presented below.

$g_{p p}=\gamma_{c} e_{l}$, and $g_{\text {revest }}=\gamma_{\text {revest }} e_{\text {revest }}$,

where $g_{p p}$ and $g_{\text {revest }}$ represent the load of the slab's own weight and coating, respectively; $\gamma_{c}$ and $\gamma_{\text {revest }}$ determine the specific weight of the concrete and the coating material; $e_{l}$ and $e_{\text {revest }}$ are the thickness of the slab and the coating. In addition, the usage load should be calculated, according to NBR 6120:1980 [22], which expresses the calculation values for building structure loads. Usage loads are also defined as accidental loads and their effect may vary according to the number of floors that act on the analyzed element [23]. The proportion of reduction ratio for these loads are as follows: for 1 to 3 floors is $0 \%$, for 4 floors is $20 \%$, for 5 floors is $40 \%$ and for 6 or more is $60 \%$. Then, the sum of all the loads applied to the slab is then multiplied by the area of influence that the slab has on a beam so that the linearly distributed load of the slab on the beam is determined.

\section{Loading on the beams}

The loads applied to the beams are distributed along their length, coming from the walls, slabs, and own weight. The beams can also receive concentrated loads from secondary beams that are supported [24]. Thus, the loads applied to the beams are calculated as:

$$
g_{p a r}=\gamma_{t i j} e_{t i j} h_{p a r} \text { and } g_{p p}=\gamma_{c} A_{v},
$$

where $g_{p a r}$ and $g_{p p}$ represent the load of walls and the own weight of the beams, respectively; $\gamma_{t i j}$ and $\gamma_{c}$ are the specific weights of brick and concrete; $e_{t i j}$ is the thickness of the brick; $h_{p a r}$ determines the height of the wall; Av is the crosssectional area of the beam.

\section{Loading on the columns}

In the concrete structure, the columns have the function of receiving the loads from the beams and, in addition, it is necessary to consider the column's own weight [21]. The load generated by the weight of the column is obtained by:

$$
g_{p p}=\gamma_{c} h A_{p},
$$

where $g_{p p}$ represents the column load; $\gamma_{c}$ the specific weight of the concrete; $A_{p}$ is the cross-sectional area of the column.

\section{RESULTS AND DISCUSSIONS}

In this section three numerical examples are presented to show the applicability of the proposed optimization methodology. The first numerical example is related to the calculation of static wind forces. Then, the optimization method is tested with a well-known benchmark example obtained from literature. Finally, a practical case especially developed for this work is presented, with the objective of calculating the force caused by the static and dynamic effects of the wind, and performing the optimization of the cross sections, having the minimum weight as the objective function. The practical case proposes an analysis of a 2D structure, which represent a simplification of a 3D real structure. However, a more realistic analysis should include a full 3D formulation, which is not within the scope of the present work.

\subsection{Static Effect of the Wind}

The plane frame used for the analysis of the wind has a total height of $21.60 \mathrm{~m}$, with the width of the facade in the $\mathrm{X}$-direction equal to $32 \mathrm{~m}$ and in the Y-direction equal to $9 \mathrm{~m}$. The building arrangement is composed from eight pavements. To assess the wind forces, the same values presented in Costa's [23] work were used, with the basic wind speed being $33 \mathrm{~m} / \mathrm{s}$, the coefficients $S 1$ and $S 3$ equal to 1.00 , the drag coefficient for the $\mathrm{X}$ direction is 1.235 and the $\mathrm{Y}$ direction is 0.765 . The value of the coefficient $S 2$ and the height of the floors are shown in Table 1. 
Table 1. Data for the calculation of wind forces [23].

\begin{tabular}{|c|c|c|c|c|c|}
\hline Floor & Height (m) & Factor $S 2$ & Floor & Height (m) & Factor $S 2$ \\
\hline $1^{\circ}$ & 2.70 & 0.720 & $5^{\circ}$ & 13.50 & 0.751 \\
\hline $2^{\circ}$ & 5.40 & 0.720 & $6^{\circ}$ & 16.20 & 0.773 \\
\hline $3^{\circ}$ & 8.10 & 0.720 & $7^{\circ}$ & 18.90 & 0.792 \\
\hline $4^{\circ}$ & 10.80 & 0.724 & $8^{\circ}$ & 21.60 & 0.809 \\
\hline
\end{tabular}

Each level of the slab is considered as a point for the application of wind forces, as these elements present greater rigidity. Thus, it was considered that the area of influence for each node is composed of half of the upper floor and half of the lower floor, except for the load applied on the first floor, in which the entire lower floor was considered. This methodology was also adopted for this work and the results are shown in Table 2.

The results obtained in both studies are similar, however, with small variations in wind forces when compared to the results of Costa [23], this fact could be explained by numerical truncation, for example.

Table 2. Comparison of results.

\begin{tabular}{|c|c|c|c|c|}
\hline \multirow{3}{*}{ Floor } & \multicolumn{3}{|c|}{ Wind forces $(k N)$} & \\
\hline & \multicolumn{2}{|c|}{ Direction $\mathrm{X}$} & \multicolumn{2}{|c|}{ Direction Y } \\
\hline & Costa $[23]$ & Present & Costa [23] & Present \\
\hline $1^{\circ}$ & 55.40 & 55.39 & 9.65 & 9.65 \\
\hline $2^{\circ}$ & 36.93 & 36.93 & 6.43 & 6.43 \\
\hline $3^{\circ}$ & 37.15 & 36.93 & 6.47 & 6.43 \\
\hline $4^{\circ}$ & 38.75 & 37.34 & 6.75 & 6.50 \\
\hline $5^{\circ}$ & 41.34 & 40.17 & 7.20 & 6.70 \\
\hline $6^{\circ}$ & 43.62 & 42.56 & 7.60 & 7.42 \\
\hline $7^{\circ}$ & 45.67 & 44.68 & 7.96 & 7.78 \\
\hline $8^{\circ}$ & 23.32 & 23.31 & 4.07 & 4.06 \\
\hline
\end{tabular}

\subsection{Optimization Analysis}

For testing the optimization method, a well-known benchmark example was evaluated. The geometry and boundary conditions are shown in Figure 2. Here, the TLBO was used as the optimization method, with the objective of finding the cross sections of the elements that result in the minimum weight of the structure. The analyzed frame shows forces concentrated in both directions and bending moments.

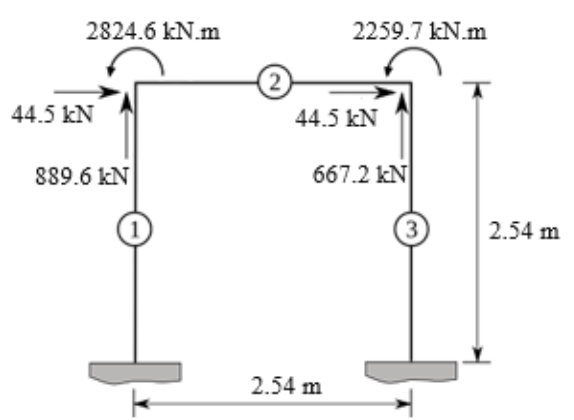

Figure 2. Plane frame optimization.

The analysis was carried out in three different cases, varying the displacement and stress constraints, according to the one presented in the work of Castro [6] and shown in Table 3. The sizing range for the areas $A_{i}$ was from 0.65 to $967.74 \mathrm{~cm}^{2}$, the modulus of elasticity $\mathrm{E}=206.84 \times 10^{3} \mathrm{MPa}$, density $\rho=7833.41 \mathrm{~kg} / \mathrm{m}^{3}$, moment of inertia $\mathrm{I}=75 \times \mathrm{A}_{\mathrm{i}} \mathrm{cm}^{4}$, and length of the neutral line $\mathrm{Y}=I /\left(9 \times \mathrm{A}_{\mathrm{i}}\right) \mathrm{cm}$. Khan et al. [25] and Castro [6] used continuous area variables in their 
analysis, and in the work carried out by Castro [6], the optimization method of genetic algorithms was used and in Khan's [25], an optimization algorithm based on constraints was developed.

Table 3. Data from the analyzed cases [6].

\begin{tabular}{cc}
\hline Case & Characteristics \\
\hline \multirow{2}{*}{ I } & Nodes restricted to displacement of $\pm 0.254 \mathrm{~cm}$. \\
\cline { 2 - 2 } II & All bars restricted to tension of $\pm 165.47 \mathrm{MPa}$. \\
\cline { 2 - 2 } III & Nodes restricted to displacement of $\pm 0.178 \mathrm{~cm}$. \\
\hline
\end{tabular}

Here, discrete variables were used with discretization between the established area limits of $0.01 \mathrm{in}^{2}$. Results are presented in Table 4.

Table 4. Comparison of results.

\begin{tabular}{|c|c|c|c|c|c|c|c|c|c|}
\hline \multirow{3}{*}{ Element } & \multicolumn{9}{|c|}{ Cross section area $\left(\mathrm{cm}^{2}\right)$} \\
\hline & \multicolumn{3}{|c|}{ Case I } & \multicolumn{3}{|c|}{ Case II } & \multicolumn{3}{|c|}{ Case III } \\
\hline & $\begin{array}{c}\text { Khan et al. } \\
{[25]}\end{array}$ & Castro [6] & Present & $\begin{array}{c}\text { Khan et al. } \\
{[25]}\end{array}$ & Castro [6] & Present & $\begin{array}{c}\text { Khan et al. } \\
{[25]}\end{array}$ & Castro [6] & Present \\
\hline 1 & 127.81 & 91.29 & 86.58 & 114.71 & 121.55 & 120.65 & 41.48 & 40.52 & 41.16 \\
\hline 2 & 679.94 & 616.45 & 608.32 & 839.16 & 873.29 & 870.58 & 299.48 & 304.77 & 303.68 \\
\hline 3 & 194.71 & 272.65 & 284.19 & 447.16 & 403.68 & 407.23 & 148.65 & 144.32 & 144.65 \\
\hline Weight (kg) & 1994.22 & 1950.32 & 1947.76 & 2787.13 & 2782.13 & 2782.00 & 974.01 & 974.00 & 973.75 \\
\hline
\end{tabular}

The results regarding the weight of the structure in the three cases analyzed were lower when using the TLBO as an optimization method, with the greatest variation occurring in case I, in which the present one studied obtained a reduction of $2.33 \%$ in relation to the weight found by Khan et al. [25]. The efficiency of the TLBO method for the optimization of frames, in which the results found in this study were lower when compared to those presented in the literature.

\subsection{Study Case}

In this work, a plane frame that simulates a simple building was analyzed, in which both the loads considered permanent in the structure and the variable loads were applied. For this example, it was considered a frame with 30 meters high, with 10 floors, and each floor has 3 meters in height. The facade is 10 meters long and the distance between the columns is 5 meters, as shown in Figure 3.
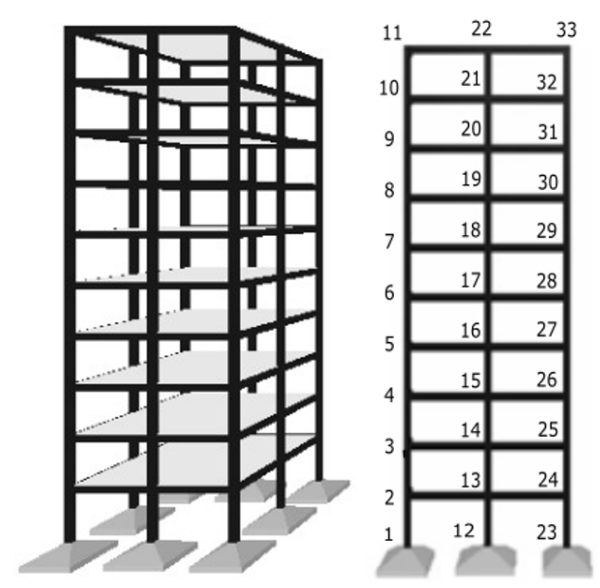

Figure 3. Case study frame. 
For the structure of this frame, only the use of simple concrete was considered, with concrete fck equal to $50 \mathrm{MPa}$. The characteristics of the materials, according to NBR 6120:1980 [22], are: slab subfloor with specific weight of $21 \mathrm{kN} / \mathrm{m}^{3}$ and $2.0 \mathrm{~cm}$ thick; ceramic coating $1.0 \mathrm{~cm}$ thick, having a specific weight of $18 \mathrm{kN} / \mathrm{m}^{3}$; the slab $10 \mathrm{~cm}$ high by 5 meters long, where the specific weight of the concrete used was $24 \mathrm{kN} / \mathrm{m}^{3}$; the building walls are 2.80 meters high, using a $9 \mathrm{~cm}$ thick perforated brick with a specific weight of $13 \mathrm{kN} / \mathrm{m}^{3}$. For the utilization load, considered as a place for general use rooms and bathrooms, $2 \mathrm{kN} / \mathrm{m}^{2}$ was adopted. To determine the low turbulence wind loads, the basic wind speed was $30 \mathrm{~m} / \mathrm{s}$, the topographic factor $S 1$ was 1.0 , the probabilistic factor $S 3$ was 1.0 and the drag coefficient equal to 0.8 . To determine the $S 2$ factor, the building belongs to category IV, in terms of the roughness of the land, and class $\mathrm{B}$, in relation to its dimensions. The parameter for analyzing the wind effect are as follows: $p=0.125, b=0.85$, $F_{r}=0.98$, for the static representation; while $\gamma=1.2, \xi=1.4, p=0.23$, and $b=0.71$, for the dynamic representation.

It is worth to point out that an initial linear dynamic analysis was accounted to obtain the first natural frequencies of the structure, being the first five frequencies: $0.81 \mathrm{~Hz}, 2.51 \mathrm{~Hz}, 4.38 \mathrm{~Hz}, 6.48 \mathrm{~Hz}$ and $8.86 \mathrm{~Hz}$, respectively. The FEM commercial software Abaqus 2020 student edition was used to this end. The value of the first natural frequency $(0.81 \mathrm{~Hz})$ clearly does not attend the Brazilian normative NBR 6118:2014 [11], which requires a minimum value of $4.2 \mathrm{~Hz}$ for the first natural frequency, thus, a dynamic analysis is herewith justified.

\section{Definition of structural optimization parameters}

To carry out the analysis of the structure presented above, the NBR 6118:2014 [11] standard was used according to the class of concrete adopted $\left(f_{c k} 50 \mathrm{MPa}\right)$, the material's elasticity module and the calculation stress limits. To determine the modulus of elasticity it was adopted that the coarse aggregate to be used in the concrete will be the basalt, resulting in a value of $43.95 \mathrm{GPa}$. The ultimate stress in compression and traction were $25.3 \mathrm{MPa}$ and $1.7 \mathrm{MPa}$, respectively. Regarding the limit displacement used in the structure calculation, it was considered $H / 1700$, as presented in the item 13.3 of NBR 6118:2014 [11], where $H$ is the total height of the building. Considering the analysis for the ultimate limit state of the structure, an equal weighting coefficient of 1.4 was used for the combination of permanent and variable actions.

Two groups of areas were defined for the optimization of the structure, one corresponding to the columns and the other to the beams. For the columns, a square section was used, with a minimum width of $19 \mathrm{~cm}$ and a maximum of $70 \mathrm{~cm}$, resulting in a minimum area of $361 \mathrm{~cm}^{2}$ and a maximum area of $4900 \mathrm{~cm}^{2}$. As for the beams, it was adopted that the base would be fixed at $15 \mathrm{~cm}$ and the height could vary from $20 \mathrm{~cm}$ to $60 \mathrm{~cm}$, with that the minimum area would be $300 \mathrm{~cm}^{2}$ and the maximum $900 \mathrm{~cm}^{2}$.

As established by Camp and Farshchin [14], for the optimization process to present good results convergence, a population of 75 students was adopted for this study, for the teacher factor $\left(F_{T}\right)$ the value of 2 and for the exponent of the penalty $(\varepsilon)$, the value of 2 was also adopted. At each iteration, 150 analyzes are performed, and the best result will be determined when 7500 analyzes are performed without changes, that is, 50 iterations, or until reaching the limit maximum of 200 iterations. To carry out the optimization study, the structure was divided into two main groups, one for beams and the other for columns. Each group was subdivided into three, in which the first went to the elements up to the 4th floor, the second group up to the 7th floor and the third group up to the 10th floor, both for beams and columns. In Table 5 the elements are identified in each group through the connection nodes. All elements that belong to the same group will have the same cross-sectional area.

Table 5. Division of the structure into groups.

\begin{tabular}{|c|c|c|}
\hline Group & Type & Elements \\
\hline 1 & \multirow{3}{*}{ Column } & $\begin{array}{c}1:(1,2), 2:(2,3), 3:(3,4), 4:(4,5), 11:(12,13), 12:(13,14), 13:(14,15), 14:(15,16), 21:(23,24), 22:(24,25), \\
23:(25,26), 24:(26,27)\end{array}$ \\
\hline 2 & & $5:(5,6), 6:(6,7), 7:(7,8), 15:(16,17), 16:(17,18), 17:(18,19), 25:(27,28), 26:(28,29), 27:(29,30)$ \\
\hline 3 & & $8:(8,9), 9:(9,10), 10:(10,11), 18:(19,20), 19:(20,21), 20:(21,22), 28:(30,31), 29:(31,32), 30:(32,33)$ \\
\hline 4 & \multirow{3}{*}{ Beam } & $31:(2,13), 32:(3,14), 33:(4,15), 34:(5,16), 41:(13,24), 42:(14,25), 43:(15,26), 44:(16,27)$ \\
\hline 5 & & $35:(6,17), 36:(7,18), 37:(8,19), 45:(17,28), 46:(18,29), 47:(19,30)$ \\
\hline 6 & & $38:(9,20), 39:(10,21), 40:(11,22), 48:(20,31), 49:(21,32), 50:(22,33)$ \\
\hline
\end{tabular}

\section{DISCUSSION}

During the execution of the structural optimization some parameters are fixed, such as the characteristics of the material used in the structure, in this case the concrete, and the constraints of displacement and stress that were 
considered. The parameters that are of variable characteristics are the intervals adopted for the cross-sectional areas, whose purpose of optimization is to find the cross-sections values that minimize the structural weight and that meet the imposed constraints. Loads acting on the structure can be classified into external and internal loads. The external loads are determined by the action of the winds, so that their values do not vary during the optimization process, as they do not depend on the cross-sectional area of the elements. The area of influence used in the calculation of wind forces was considered according to the methodology presented in the example in section 3.1. Thus, Table 6 presents the values obtained for wind forces considering the static model and the simplified dynamic model. Internal loads are determined considering the cross-sectional area of the elements, i.e., these loads vary during the optimization process and, therefore, do not have fixed values. The internal loads are determined by the concrete structure itself, through the loads of slabs.

The forces in the static model were superior to the forces calculated by the simplified model on the first floors, whereas on the last floors the values were already closer, and, on the last two floors, the forces of the simplified model have already become greater. This same relationship occurred in a work developed by Almeida and Vidoto [26], who stressed the importance of performing this dynamic analysis so that these major forces are evaluated and considered during the design project.

Table 6. Forces caused by the wind.

\begin{tabular}{ccc}
\hline Floor & Static model $(\mathbf{k N})$ & Simplified dynamic model (kN) \\
\hline $1^{\mathbf{0}}$ & 10.20 & 3.50 \\
\hline $2^{\mathbf{0}}$ & 8.09 & 3.67 \\
\hline $3^{\mathbf{0}}$ & 8.95 & 4.92 \\
\hline $4^{\circ}$ & 9.62 & 6.12 \\
\hline $5^{\circ}$ & 10.17 & 7.32 \\
\hline $6^{\circ}$ & 10.64 & 8.51 \\
\hline $7^{\circ}$ & 11.06 & 9.69 \\
\hline $8^{\circ}$ & 11.44 & 10.89 \\
\hline $9^{\circ}$ & 11.78 & 12.08 \\
\hline $1^{\circ}$ & 6.05 & 6.64 \\
\hline
\end{tabular}

The wind forces in the static model do not vary much from one floor to the next, as the dependence on height is only determined by the factor $S 2$. Thus, even if the height increases, the strength value undergoes small changes. In the case of the simplified dynamic, the height establishes a direct relationship for the determination of the dynamic pressure and, with this, with each floor the forces present greater variations in relation to the previous one.

The results obtained, from the structural optimization, of the cross sections of the column and beam elements as well as the weight of the structure, are presented in Table 7, considering that in the first case, no forces were applied due to the wind in the structure and in the in other cases, the forces applied were according to the type of wind analysis that was considered, whether static or dynamic. According to the results presented in Table 7, when the analyzed structure was optimized without considering the loads caused by the action of the wind, the structural elements of both columns and beams presented the areas of minimum cross sections, as in this case there was only consideration of loads related to the calculation of the concrete structure itself. In the other two cases in which the wind forces were considered, the values of the areas of the structural elements underwent significant variations, as these forces are considered to have a relevant influence on the behavior of the structure.

Table 7. Cross sections and structure weight.

\begin{tabular}{|c|c|c|c|c|c|c|}
\hline \multirow{2}{*}{ Group } & \multicolumn{2}{|c|}{ Analysis without wind forces } & \multicolumn{2}{|c|}{ Analysis with static wind } & \multicolumn{2}{|c|}{ Analysis with dynamic wind } \\
\hline & Dimensions (cm) & Area $\left(\mathrm{cm}^{2}\right)$ & Dimensions (cm) & Area $\left(\mathrm{cm}^{2}\right)$ & Dimensions (cm) & Area $\left(\mathrm{cm}^{2}\right)$ \\
\hline 1 & $19 \times 19$ & 361 & $50 \times 50$ & 2500 & $66 \times 66$ & 4356 \\
\hline 2 & $19 \times 19$ & 361 & $39 \times 39$ & 1521 & $36 \times 36$ & 1296 \\
\hline 3 & $19 \times 19$ & 361 & $28 \times 28$ & 784 & $25 \times 25$ & 625 \\
\hline 4 & $15 \times 20$ & 300 & $15 \times 52$ & 780 & $15 \times 60$ & 885 \\
\hline 5 & $15 \times 20$ & 300 & $15 \times 48$ & 720 & $15 \times 40$ & 600 \\
\hline 6 & $15 \times 20$ & 300 & $15 \times 46$ & 690 & $15 \times 42$ & 630 \\
\hline Weight (kg) & \multicolumn{2}{|c|}{14997.600} & \multicolumn{2}{|c|}{54176.400} & \multicolumn{2}{|c|}{67435.920} \\
\hline $\mathrm{N}^{0}$ iterations & \multicolumn{2}{|l|}{55} & \multicolumn{2}{|l|}{87} & \multicolumn{2}{|l|}{79} \\
\hline $\mathrm{N}^{\circ}$ analyzes & \multicolumn{2}{|l|}{8435} & \multicolumn{2}{|c|}{13299} & \multicolumn{2}{|c|}{12083} \\
\hline
\end{tabular}


When comparing only the weight, the structure showed an increase, compared to the analysis without considering the wind forces, of approximately $261.23 \%$ and $349.64 \%$, for the analysis with static wind and dynamic wind, respectively. When analyzing the weight of the structure in the two cases in which the wind forces were considered, the highest value was found in the analysis with the dynamic wind, but it is observed that this difference in weight was due to the fact of the groups 1 and 4 the columns and the beams up to the fourth floor have larger sections, as the other groups have smaller sections than in the static analysis. As the wind forces in the dynamic analysis were smaller, the sections reduced in size, however, on the last floors these forces were higher and with that the structure presented larger sections at the base so that it would be more resistant to the efforts caused by the wind forces in the upper part of the frame. Thus, the higher the structure, the greater the need to verify its behavior regarding the dynamic characteristics of wind forces and not just the static effect. Figure 4 shows, for the three cases analyzed, the convergence process of the objective function and the optimized structure with the cross-sectional areas in proportion. According to Figure 4, the convergence of the TLBO method occurs with few iterations, with the greatest reduction at the beginning of optimization occurred in the case in which the dynamic wind was considered. Although more iterations are performed than the amount presented, in iteration 40 there has already been convergence to the final value. The cross-sectional areas presented in Table 7 can be observed in proportion in Figure 4 through the illustrations of the structure in each case.

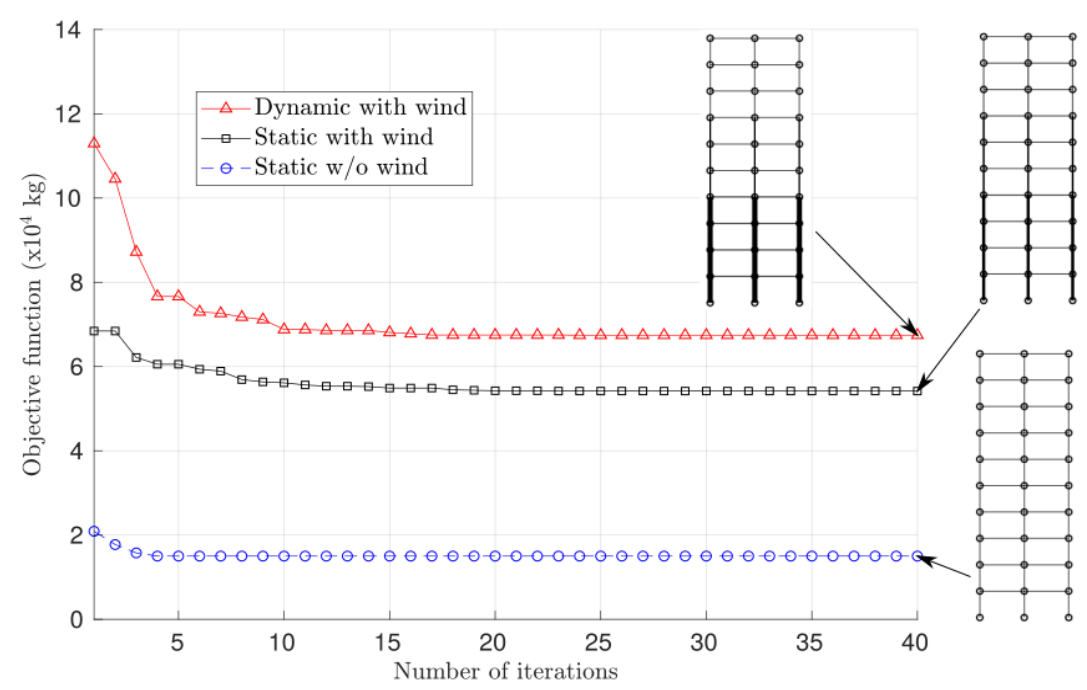

Figure 4. Convergence process for the three cases analyzed.

\section{CONCLUSIONS}

The main objectives of this paper were to analyze the influence of wind action on a building, considering both the static and simplified dynamic model loads of NBR 6123:1988 [12], as well as to perform the optimization of the structural weight of a building through a 2D model. Both objectives were also analyzed together, through the application of the practical case. From this paper, the following conclusions were obtained:

- Regarding the wind action, the static model presented for most of the points of application of forces a higher value than the simplified dynamic model, however the forces generated by the dynamic model were higher than the static model in the last floors, because in this model there is consideration of the height of the floor and the higher it is, the greater the influence of the wind, a parameter that is not considered in the static model.

- From the cases analyzed in the structural optimization it was obtained that the simplified dynamic model was the one that presented the greatest weight, whose cross-sectional areas were larger than the static model only in the structural elements of the lower part of the structure, because as the wind forces of the dynamic model were higher in the last floors the efforts generated in the lower region were greater.

- According to the convergence process for the cases analyzed in the optimization, the TLBO method that was used showed fast convergence, because with few iterations the final value was already obtained.

- The methodology herewith presented can simplify real structures analysis to a 2D frame optimization model, which can be useful as a first design result. In the case of more realistic building cases, it is necessary to expand the 
methodology and perform the modelling to analyze a 3D structure, implying into the consideration of 3D frame elements, for example.

- For this paper, the wind action loads were considered only in relation to two models of the NBR 6123:1988 [12] standard, because one of the objectives of the paper was to verify the application of the methods recommended by the standard. However, if the objective is related to the analysis of the wind action in situations with a high degree of similarity with the real wind, it is necessary to consider the non-deterministic nature of the winds, with which one can apply, e.g., the Synthetic Wind Method that uses Monte Carlo simulation to determine the loads.

- Through the proposed methodology it is possible to determine an optimized structure through the weight objective function and considering the constraints of displacements and stresses. A possible expansion of the modelling carried out would be to consider the effect of the soil-structure interaction, so that the pressure that the structure causes in the soil can be analyzed and how this interaction influences the optimization.

\section{REFERENCES}

[1] Z. A. Siddiqi, R. Hameed, and U. Akmal, "Comparison of different bracing systems for tall buildings," Pak. J. Engg. Appl. Sci, vol. 14, pp. 17-26, Jan 2004.

[2] R. A. Souza, “Controle passivo/ativo das oscilações de estruturas esbeltas por meio de dispositivos fluido-dinâmicos,” M.S. thesis, Fed. Univ. Rio de Janeiro, Rio de Janeiro, 2003.

[3] H. L. Soriano, Introdução à Dinâmica das Estruturas. Rio de Janeiro: Elsevier, 2014.

[4] P. Mendis, T. Ngo, N. Haritos, and A. Hira, "Wind loading on tall building," Eletronic J. Struct. Eng., vol. 7, pp. 41-54, 2007.

[5] A. Barile, L. S. Bastos, and J. G. S. Silva, "Human comfort assessment of buildings subjected to nondeterministic wind dynamic loadings," Rev. IBRACON Estrut. Mater., vol. 13, no. 4, pp. 1-13, 2020, http://dx.doi.org/10.1590/S1983-41952020000400002.

[6] L. C. L. B. Castro, “Algoritmo genético para otimização de estruturas reticuladas,” M.S. thesis, Univ. Brasília, Brasília, 2003.

[7] F. Gomez, B. F. Spencer Jr., and J. Carrion, "Topology optimization of buildings subjected to stochastic wind loads," Probab. Eng. Mech., vol. 64, 103127, 2021.

[8] L. S. Tapajós, J. A. T. Ferreira, A. F. Lima No., M. R. Teixeira, and M. P. Ferreira, "Effect of wind in the design of reinforced concrete buildings," Rev. IBRACON Estrut. Mater., vol. 9, no. 6, pp. 883-910, 2016.

[9] M. Kripka, J. T. Boscardin, and S. D. Casteli, "Topology optimization of reinforced concrete plane frames", Rev," Sul-americana Eng. Estrutural, vol. 13, no. 2, pp. 45-53, 2016.

[10] B. D. Breda, T. C. Pietralonga, and E. C. Alves, "Optimization of the structural system with composite beam and composite slab using Genetic Algorithm," Rev. IBRACON Estrut. Mater., vol. 13, no. 6, e13602, 2020.

[11] Associação Brasileira de Normas Técnicas. Projeto de Estruturas de Concreto - Procedimento, NBR 6118, 2014.

[12] Associação Brasileira de Normas Técnicas. Forças Devidas ao Vento em Edificacações, NBR 6123, 1988.

[13] C. V. Camp, "Design of space trusses using big bang-big crunch optimization," J. Struct. Eng., vol. 133, pp. 999-1008, 2007, http://dx.doi.org/10.1061/(ASCE)0733-9445(2007)133:7(999).

[14] C. V. Camp and M. Farshchin, "Design of space trusses using modified teaching-learning based optimization," Eng. Struct., vol. 6263, pp. 87-97, 2014, http://dx.doi.org/10.1016/j.engstruct.2014.01.020.

[15] R. V. Rao, V. J. Savsani, and D. P. Vakharia, "Teaching-learning-based optimization: a novel method for constrained mechanical design optimization problems," Comput. Aided Des., vol. 43, no. 3, pp. 303-315, 2011, http://dx.doi.org/10.1016/j.cad.2010.12.015.

[16] V. Toğan, "Design of planar steel frames using teaching-learning based optimization," Eng. Struct., vol. 34, pp. 225-232, Jan 2012, http://dx.doi.org/10.1016/j.engstruct.2011.08.035.

[17] E. S. Chávez, “Análise estrutural de edifício alto submetido às pressões flutuantes induzidas pela ação do vento,” M.S. thesis, Fed. Univ. Minas Gerais, Belo Horizonte, 2006.

[18] M. Islam, A. Siddique, and A. Murshed, "Sustainable development in drift control of tall buildings due to wind load: critical analyses of the structural systems," in Inter. Conf. Civ. Eng. Sustain. Dev., 2012, pp. 1-7.

[19] C. Slongo, “Análise dinâmica de uma torre metálica de telecomunicações utilizando o método do vento sintético,” M.S. thesis, Fed. Univ. Paraná, Curitiba, 2016.

[20] R. M. B. Cerutti, “Estudo comparativo de métodos para análise aerodinâmica de estruturas submetidas ao vento turbulento,” M.S. thesis, Fed. Univ. Rio de Janeiro, Rio de Janeiro, 2017.

[21] P. R. Santos, “Análise e cálculo de elementos estruturais em concreto armado de um edifício residencial,” M.S. thesis, Fed. Univ. Santa Catarina, Florianópolis, 2014.

[22] Associação Brasileira de Normas Técnicas, Cargas para o Cálculo de Estruturas de Edificações, NBR 6120, 1980.

[23] J. P. D. Costa, A Influência do Efeito de Vento na Análise Estrutural de Edificios. Belo Horizonte: Univ. Fed. Minas Gerais, 2013. 
[24] P. S. S. Bastos, Fundamentos do Concreto Armado. Bauru: Univ. Est. Paul., 2019.

[25] M. R. Khan, K. D. Willmert, and W. A. Thornton, "An optimality criterion method for large-scale structures," AIAA J., vol. 17, pp. 753-761, May 1979, http://dx.doi.org/10.2514/3.61214.

[26] D. C. Almeida and T. A. H. Vidoto, “Análise comparativa dos métodos estático e dinâmicos da ação do vento em edifícios esbeltos de concreto armado segundo a NBR 6123/1988,” M.S. thesis, Fed. Technol. Univ. Paraná, Curitiba, 2013. [Online]. Available: http://repositorio.roca.utfpr.edu.br/jspui/handle/1/2130

Author contributions: EUC: conceptualization, investigation, methodology, validation. RQR: conceptualization, formal analysis, investigation, methodology, supervision. LQM: supervision, writing-review \& editing. FFK: conceptualization, investigation. PSS: conceptualization, investigation. APCQ: conceptualization, writing-review \& editing.

Editors: Leandro Mouta Trautwein, Guilherme Aris Parsekian 